\title{
Gender, interest, and prior experience shape opportunities to learn programming in robotics competitions
}

\author{
Eben B. Witherspoon*, Christian D. Schunn, Ross M. Higashi and Emily C. Baehr
}

\begin{abstract}
Background: Robotics competitions are increasingly popular and potentially provide an on-ramp to computer science, which is currently highly gender imbalanced. However, within competitive robotics teams, student participation in programming is not universal. This study gathered surveys from over 500 elementary, middle, and high school robotics competition participants to examine (1) whether programming involvement in these competitions is associated with motivation to pursue additional programming experiences and (2) whether opportunities to learn programming varied by gender, age, and competition type.

Results: Results showed a significant association of students' programming involvement with their motivation to learn more programming. Interestingly, in the youngest groups/entry-level competitions, girls were heavily involved in programming. Unfortunately, in older/more advanced competitions, girls were generally less involved in programming, even after controlling for prior programming experience. These gendered effects were substantially explained by programming interest.

Conclusions: While robotics competition experiences may motivate students to learn more programming, gender gaps in programming involvement persist in these learning environments and appear to widen as students grow older and enter more advanced competitions. Therefore, addressing gender imbalances in programming will likely require greater attention to particular curricular and pedagogical characteristics of robotics competitions that support girls' interest and involvement in programming.
\end{abstract}

Keywords: Robotics, Programming, Computational thinking, Gender equity, Opportunities to learn

\section{Background}

Over the past decade, robotics competitions have emerged as a popular and productive informal learning environment that can potentially increase student interest in math and science and motivate students to pursue science, technology, engineering and mathematics (STEM) careers (Hendricks et al. 2012; Petre \& Price 2004). Robotics programming is seen as playing a particularly important role in inspiring and developing students' fluency in computational thinking, which is gaining recognition as an essential twenty-first century skill within K-12 education (Alimisis 2013; Barr \& Stephenson 2011; Eguchi 2015; Grover \& Pea 2013; Wing 2006). In addition to

\footnotetext{
* Correspondence: eben.witherspoon@pitt.edu

Learning Research and Development Center, University of Pittsburgh, 3939 O'Hara Street, Pittsburgh, PA 15260, USA
}

the increasing utility of programming and computational thinking in our everyday lives, computer science (CS) is also a high paying and quickly growing field where historically, the supply of an adequately educated workforce has struggled to keep up with demand. According to the Bureau of Labor Statistics (2014), 8 of the 10 occupations within the field of Computer and Information Technology are expected to have growth rates larger than $11 \%$ through 2022.

Despite this high level of growth in computer science, it is well documented that women are highly underrepresented in the field, and the gap between men and women entering computer science careers continues to widen. According to the 2013-2014 Computing Research Association Taulbee report, almost $86 \%$ of recipients of bachelor's degrees in computer science in the USA in 2014 were male. Although the reported number of CS 
bachelor degrees earned increased by $14 \%$ from 2013 to 2014, the proportion of females receiving CS degrees during that time decreased (Zweben \& Bizrot 2015). Gender differences in STEM fields are a continued concern for researchers seeking to understanding gender gaps in fields like CS (Else-Quest et al. 2010). Some studies claim a biological basis for differences in achievement and preference between males and females (BaronCohen 2003; Geary 1998; Kimura 1999). However, there is growing empirical evidence to support the hypothesis that observed gender differences are largely socially and culturally constructed and that few innate psychological differences in cognitive ability and preference exist between genders (Bussey \& Bandura 1999; Hyde 2005; Hyde \& Linn 2006; Spelke 2005). Research suggests that women's interest in continuing to pursue careers in predominately male fields like CS is related to the level of self-confidence in their ability in that field, and early opportunities to engage in computing can play a significant role in the development of this confidence (Gürer \& Camp 2002; Zeldin \& Pajares 2000). Lent and colleagues have suggested that interest and self-efficacy, the belief in ones' ability to perform successfully, interact with social and environmental supports and barriers to determine persistence towards career goals (Lent et al. 2008). Furthermore, CS prerequisites in college often assume some knowledge of informal jargon and in-group behaviors common to computer science. Having fewer prior informal CS experiences, relative to their male counterparts, can further reinforce girls' low levels of confidence as they enter CS majors, even when actual levels of academic preparation are comparable (Blickenstaff 2005; Margolis \& Fisher 2002). A key factor in sustaining girls' interest in pursuing computing careers may be engaging them in informal computing experiences that support their involvement in computing practices and remove barriers to their identity development as members of the computer science community.

Research on situated learning and social cognition provides a theoretical framework that may further explain this phenomenon. For decades, researchers in the learning sciences have claimed that direct participation in the practices of a particular professional community is related to the development of both the particular disciplinary skills of that community as well as the formation of an identity as an expert in that community (Lave \& Wenger 1991). Informal learning environments are thought to offer learners rich opportunities to learn not only through the application of skills in context but also through an apprenticeship-like enculturation into the language and norms of a particular domain (Brown et al. 1989). This analytic stance is particularly appropriate for informal educational robotics, where team mentors are often industry professionals, and participation in the team entails scaffolded engagement in the authentic practices of a profession, similar to traditional apprenticeship.

However, opportunities to participate in these professional practices do not exist in isolation from the particular socio-historical environment in which these communities operate (Holland et al. 1998). For example, studies have shown that girls who persist in their pursuit of science careers are challenged to negotiate the culturally constructed and often competing identities of "feminine" and "scientific" (Archer et al. 2012; Kleinman 1998). Holland and colleagues describe these socially and culturally constructed environments as "figured worlds," where "particular characters and actors are recognized, significance is assigned to certain acts, and particular outcomes are valued over others" (Holland et al. 1998, pg. 52). Social cognitive theory suggests that a learner, their behavior, and the learning environment are reciprocally deterministic; that is, a learner's affective and cognitive engagement and the learning environment are continuously coconstructed through interactions and experiences the learner has with that environment (Bandura 1989). Situated within socially reproduced learning environments, participation in programming activities on robotics teams may reflect figured worlds of "robotics" and "programming" that restrict access to certain roles for girls and other traditionally underrepresented groups.

The gender gap in computer science interest between boys and girls appears as early as middle school (Doerschuk et al. 2007). Therefore, a significant effort has been made to develop $\mathrm{K}-12$ interventions that improve girls' attitudes towards computer science and maintain their interest in computing through high school. Despite this effort, in recent years the USA has experienced a decline in the numbers of traditional secondary computer science classes that are being offered. A study by the Computer Science Teachers Association shows that the number of secondary schools offering introductory computer science classes decreased $13 \%$ from 2005 to 2009 (CSTA 2009). Classes that do still exist remain largely ineffective at inspiring and maintaining the interest of girls through high school. Of those schools that offer advanced placement-level computer science classes (which are treated as equivalent to university courses and influence acceptance into universities), only $19 \%$ of students taking those classes were female in 2013, in contrast to $59 \%$ female for AP Biology classes that same year (The College Board 2014).

Preliminary studies of robotics programs have shown them to be more effective at involving girls in science and engineering, with some reports showing that girls who were involved in robotics programs are almost 
twice as likely to enroll in a STEM-related major in college as students in a matched control sample. However, of those female participants in robotics who chose to pursue a major in a STEM field, still less than $2 \%$ were in computer science (Melchior et al. 2005). Therefore, while robotics programs have been shown to provide rich experiences that motivate girls to pursue STEM careers more generally, these environments have somehow been less motivating for girls to pursue specific CS career pathways.

Some previous studies of pilot robotics camps and workshops have investigated girls' interest in computer science (Doerschuk et al. 2007; Hamner et al. 2008; Modekurty et al. 2014) and suggest that particular program characteristics, like the presence of female mentors or a social narrative approach to problem-solving, may be related to increased computer science career interest, knowledge, and self-confidence for girls. However, no prior research has looked across competitive robotics programs, which vary along many dimensions. A recent survey of 345 VEX Robotics mentors, for example, showed that while middle school teams had an even amount of male and female mentors, in high school, the percentage of female mentors was less than $27 \%$ (Hendricks et al. 2012). Some competitions also specifically grade on teamwork, which incentivizes integration of all team members. Additionally, different competitions target specific age groups. In FIRST Robotics, FIRST Lego League (FLL) is restricted to students age 14 and under, while FIRST Robotics Competition (FRC) is for high-school aged students. As children get older, gender stereotypes may have an increasing impact on which roles they choose to adopt on the team. There can also be wide variation within competitions by age. VEX IQ teams can range from age 8 to 14 , while VEX EDR teams range from age 11 to 18 ; there can be considerable motivational and social expectation changes over such age ranges. Further, competitions also vary in sizes of the teams (e.g., FLL teams can have no more than 10 students; FRC teams must have at least 10 students and typically have 25 students); as teams grow in size, role differentiation is more likely to occur. More research is therefore needed to identify the particular characteristics of robotics programs that contribute to or limit girls' interest in computer science as they develop during their $\mathrm{K}-12$ years.

In this study, we analyzed surveys from over 500 participants across multiple robotics competitions from elementary to high school, to explore the effects of different levels of access to student programming involvement, and the relationship between involvement and motivation to pursue additional opportunities to learn programming. We build upon prior motivational literature that argues for robotics competitions as a potential on-ramp for students to pursue additional STEM experiences, with our focus on the impact these programs have on motivation in computational thinking and computer science through programming. However, if access to programming opportunities is not equal by gender, then these competitions may increase rather than decrease the participation gap in computer science.

\section{Methods}

\section{Sample}

Our study was conducted at five robotics competitions in the northeast region of the USA. Three competitions were from the very popular FIRST organization, and two were from the newer but quickly expanding VEX organization; in both organizations, we list the competitions in the order of the youngest to oldest age groups. Specifically, the competitions sampled were FIRST Lego League (FLL; $n=155$ ), FIRST Tech Challenge (FTC; $n=$ 76), FIRST Robotics Competition (FRC; $n=123$ ), VEX IQ (VIQ; $n=41$ ), and VEX EDR (VEX; $n=27$ ), as well as two mixed competitions $(n=77)$, producing a total $N$ of 502 participants. These participants represented a diverse sample of elementary through high school students between the ages of 7 and $18(M=13.3, \mathrm{SD}=2.4)$. Two thirds of the respondents reported having prior experience at robotics competitions and slightly more than half reported having prior programming experience $(55 \%)$. Demographics of the sample were roughly representative of the school districts in which the competitions were situated; ethnically $74 \%$ identified as White, $8 \%$ identified as African American, and $8 \%$ identified as Asian. By gender, however, the competitions were predominately male (see Table 1 ). Reponses with values for gender that were missing $(n=17)$ or "other" $(n=2)$ were excluded from analysis involving those variables, as were responses from mixed competitions $(n=77)$ that made analyses by competition type difficult to interpret.

Table 1 Gender demographics by competition and age group

\begin{tabular}{lllll}
\hline & & Male & Female & Total \\
\hline Competition & FLL & $85(57 \%)$ & $63(43 \%)$ & 148 \\
& FTC & $55(74 \%)$ & $19(26 \%)$ & 74 \\
& FRC & $75(64 \%)$ & $43(36 \%)$ & 118 \\
& VIQ & $31(76 \%)$ & $9(23 \%)$ & 40 \\
& VEX & $19(73 \%)$ & $7(27 \%)$ & 26 \\
Total & & $265(65 \%)$ & $141(35 \%)$ & 406 \\
Age group & $7-9$ & $13(59 \%)$ & $9(41 \%)$ & 22 \\
& $10-12$ & $108(63 \%)$ & $63(37 \%)$ & 171 \\
& $13-15$ & $125(71 \%)$ & $52(29 \%)$ & 177 \\
& $16-18$ & $76(67 \%)$ & $37(33 \%)$ & 113 \\
Total & & $322(67 \%)$ & $161(33 \%)$ & 483 \\
\hline
\end{tabular}




\section{Materials and procedure}

Surveys were distributed at each event to representatives from robotics teams and filled out individually by team members. The survey consisted of 12 Likert scale items and 16 binary items about relevant student interests, motivation to pursue additional opportunities to learn, team collaboration and team goals, and 5 general demographic questions about students and their team (see Additional file 1 for relevant sample items). To ensure high rates of survey completion, the survey was purposely kept short. At the high school level, gift cards were offered as incentives for completing the survey.

\section{Motivation to learn programming}

Motivation to pursue additional opportunities to learn programming was measured with one item ("This robotics program inspires me to learn more programming"), scored along a 4-point Likert scale ( 1 = NO!, $2=$ no, 3 =yes, 4 =YES!). This Likert scale works well across age groups because of its simple and intuitive wording and has been used in many validated instruments, including those with interval scale properties that enable analysis via mean scores and linear regression (see http://activationlab.org/tools).

\section{Prior experience and interest}

Prior programming experience and prior robotics competition experience were measured through two separate binary yes or no items ("Have you [done computer programming/been to a robotics competition] before?”). Programming and robotics interest were measured with two separate items ("I love [programming/robotics]") measured along a 4-point Likert scale $(1=\mathrm{NO}$ !, $2=$ no, 3 = yes, 4 = YES!).

\section{Intensity of programming participation}

One item measured students' programming involvement within their teams, through the question "Who is responsible for programming on your team?" For these items, respondents could select any combination of the values "Me", "Teammates," and "Mentor." These responses were recoded into three categories pertaining to intensity of programming involvement: "Me" = responses of only "Me"; "Together" = responses including "Me" and any other response; and "Other" = responses excluding "Me."

\section{Demographics}

The survey also collected demographic information such as age and gender. A continuous age variable was used for all analyses; for better interpretability when displaying results, age was grouped into four categories with equal intervals: 7 to 9,10 to 12,13 to 15 , and 16 to 18 , corresponding roughly to elementary, elementary/early middle school, late middle school/early high school, and upper high school. Participants also recorded with which robotics competition they were currently participating.

\section{Analysis}

The survey data was modeled using analysis of variance (ANOVA) and ANCOVA. For all analyses, Levene's test of homogeneity of variance was first performed to determine if there was significant difference in variances between groups. In cases where large differences in standard deviation (greater than 2:1) were found, a Kruskal-Wallis non-parametric ANOVA was conducted. We conducted an initial ANCOVA to determine if there was a significant relationship between levels of programming involvement with motivation to learn more programming, controlling for prior programming, and robotics competition experience and interest. We then conducted three separate ANOVA testing for differential effects of gender on levels of programming involvement: the first (model 1) is to test for significant main effects of gender on programming involvement; the second (model 2) is to test for significant effects of competition type on programming involvement by gender; and the third (model 3) is to test for significant effects for age groups on programming involvement by gender. We ran the model 1 and model 2 analyses separately due to a high degree of association $\left(\chi^{2}=18.37, p<.001\right)$ between competition type and age. Finally, we conducted two further ANCOVAs (model 4 and model 5) to test if the gendered effects from the prior models remained consistent when controlling for all combinations of prior robotics and programming experience and prior robotics experience and programming interest. In other words, we examined whether gender differences in participation can be explained by differences in interest or differential amounts of prior experience.

\section{Results \\ Motivation \\ Is participation in robotics competitions associated with interest to learn more programming?}

Our initial analysis looked at the overall effects of programming involvement on students' motivation to learn more programming, as indicated by the survey question "This robotics program inspires me to learn more programming." The independent variable was levels of individual programming involvement, as indicated by student responses to "Who is responsible for programming on your team?" Levene's test for homogeneity of variance was significant $(F=17.69, p<.001)$, indicating particularly large standard deviation in the Others group, compared to both the Me and Together groups. Because the Others group was the larger sample, it is likely that the $F$ statistic is an overly conservative 
estimate for this analysis; thus, there is no concern about an increased type I error. Nonetheless, a KruskalWallis $\mathrm{H}$ test was also conducted and showed that motivation to learn more programming was different for the three heteroskedastic groups $\chi^{2}(2)=68.58, p<.001$.

Pairwise analyses were performed using a Dunn rank sum test (Dunn 1964) with a Bonferroni adjustment. Results show that there was no significant difference in effects $(z=.65, p=.77)$ between Me and Together, but there were significant differences in effects $(z=5.60$, $p<.001 ; z=8.31, p<.001)$ between these two categories and Others. Therefore, those who were involved in programming (alone or together) showed significantly higher motivation to learn programming than those not involved. Although the $N$ for $\mathrm{Me}$ is smaller than the other groups, the $N=42$ combined with relatively small $\mathrm{SD}$ for that group ensures that any differences between $\mathrm{Me}$ and Together must be relatively small compared to the large difference against Others. Therefore, responses were recoded into dichotomous categories for future analyses, with $\mathrm{Me}$ and Together as "Involved" and Others as "Uninvolved" (see Table 2).

Using the binary predictor "Involved" and "Uninvolved," an ANOVA of motivation to learn more programming as the dependent variable showed a significant relationship between programming involvement and motivation to learn programming, $F(1,484)=97.81, p<.001$, $\eta_{p}{ }^{2}=.17$. These main effects remained significant in an ANCOVA model including the following as covariates: prior programming and robotics competition experience, $F(1,474)=89.61, p<.001, \eta_{p}{ }^{2}=.16$; robotics and programming interest, $F(1,476)=11.52, p<.001, \eta_{p}{ }^{2}=.02$; and both experience and interest covariates, $F(1,466)=$ 13.82, $p<.001, \eta_{p}{ }^{2}=.03$. Semantically, the contrast showed a majority of students having a lukewarm positive (yes) towards learning more programming when others programmed, to a majority of students having a strong positive (YES!) towards learning more programming when they were directly involved in programming on their team (see Fig. 1).

Table 2 Sample size, mean, and SD for motivation to learn programming, by programming involvement

\begin{tabular}{clll}
\hline \multirow{2}{*}{ Who programs } & $N$ & \multicolumn{2}{l}{ Motivation to learn programming } \\
\cline { 2 - 4 }$M$ & $N$ & 3.8 & SD \\
\hline Me & 42 & 3.4 & 0.5 \\
Together & 167 & 3.7 & 0.8 \\
Others & 277 & 3.1 & 0.8 \\
Total & 486 & 3.7 & 0.5 \\
Involved & 209 & 3.7 & 0.8 \\
Uninvolved & 277 & 3.1 & 0.8 \\
Total & 486 & 3.7 &
\end{tabular}

Although the directionality of the causality is ambiguous (involvement influences motivation or motivation influences involvement), these analyses help to identify the appropriate control variables in the opportunity analysis as well as providing evidence against the possibility of negative effects of involvement on programming interest. For example, it might have been the case that those not involved were envious and therefore especially interested or those who were involved had their curiosity met and were then no longer interested. In addition, in the informal context, students might have found participating in the complex, highly competitive programming tasks frustrating and therefore demotivating.

\section{Opportunities to learn}

\section{Do girls have equal opportunities to participate in programming across robotics competitions and age groups?}

In our next set of analyses, we examined student responses separately by gender, to see if there were differential levels of involvement by gender across different robotics competitions and different age groups (see Table 2). All assumptions of homogeneity of variance were checked and found to be relatively small (less than a 2:1 difference in SD). The standardized beta coefficients from all five models for opportunities to learn by gender run in this set of analyses are reported in full in Table 4 of Appendix.

Using the dichotomous categories of programming involvement, we first ran a one-way ANOVA to evaluate the main effect of gender on programming involvement. The ANOVA for this first model (model 1) was not significant, $F(1,468)=.17, p=.68$; as a mean across all competitions and age groups, girls had equal opportunities to be involved in programming.

Next, two factorial ANOVAs were conducted to evaluate the relationship between programming involvement and gender, separately by competition types (model 2 ) and age (model 3), and test for the existence of interactions between these factors and gender. Results from model 2 show significant main effects of competition type $F(4,389)=32.28, p<.001, \eta_{p}{ }^{2}=.25$. Gender main effects were not significant, $F(1,389)=.35, p=.55$. However, the interaction between competition and gender was significant for FIRST (FLL, FTC, FRC) competitions, $F(2,327)=2.96, p<.05, \eta_{p}{ }^{2}=.02$, and not statistically significant for VEX (VIQ, VEX) competitions $F(1,62)=.27, p=.61$. In more entry-level FIRST competitions, there is a trend towards higher female than male participation in programming, whereas in the more advanced competitions, the difference reverses (see Fig. 2a). Interestingly, this pattern does not appear in VEX competitions. It is also worth noting 

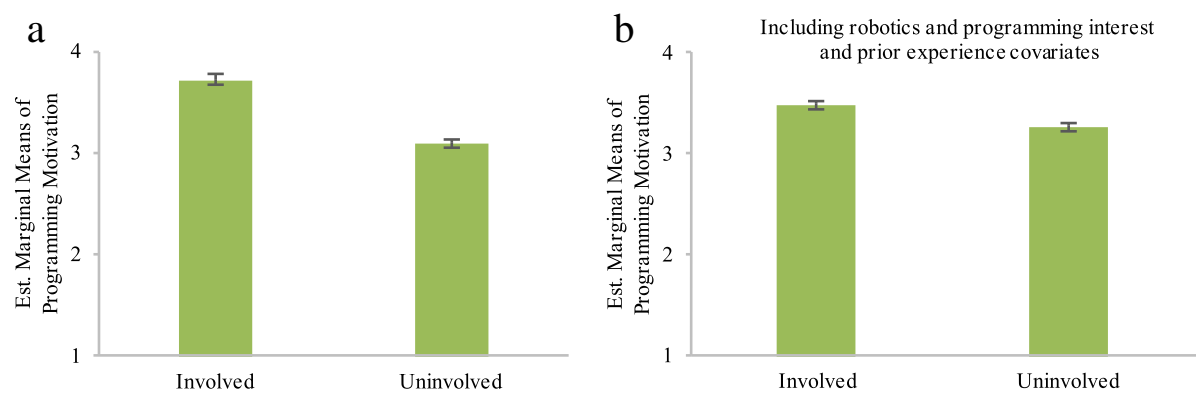

Fig. 1 Mean motivation to learn programming ( $1=$ NO!, 4 = YES!) with SE bars, by programming involvement (a), and with interest and prior experience in robotics and programming as covariates (b)

that only in the FLL competition are most children involved in programming. In all other competitions, there is a much greater level of role specialization (including mechanical design, electrical design, media design, webmasters, team spirit, scouts, and fundraising), with few children being involved in the programming at all. Most saliently, there is a 5:1 ratio in male to female participation in programming in FRC, the oldest/most advanced high school competition $\left(M_{\text {age }}=15.8, \mathrm{SD}_{\text {age }}=\right.$ 1.23). This gender participation ratio is similar to relative participation rates in AP Computer Science and undergraduate computer science majors.

Results from model 3 also show a significant interaction between age and gender on programming involvement, $F(1,463)=3.80, p<.05, \eta_{p}{ }^{2}<.01$, with significant main effects of age, $F(1,463)=46.15, p<.001$, $\eta_{p}{ }^{2}=.09$, and gender, $F(1,463)=3.77, p<.05, \eta_{p}{ }^{2}<.01$. These results are necessarily somewhat similar to the competition pattern given the age requirements of some competitions. However, there can still be separate age effects given the broad and overlapping age bands of each competition (e.g., FLL is $8-14$, FTC is roughly $12-18$, FRC is roughly $14-18$, VIQ is $8-14$, and VEX is $11-18$ ). We see relatively stronger female participation in middle elementary and then stronger male participation in middle to late high school (see Fig. 2b).
Do gender differences in opportunity to participate in programming remain across age groups and competitions, while controlling for motivational characteristics?

Before including our covariates, we first ran analyses to test for the effects of age group on interest and prior experience in robotics and programming by gender, to examine whether these characteristics follow the same gendered age changes-if not, they cannot be an explanation for the differential gender participation (Table 3). Results show no significant interactions of age and gender on both robotics interest, $F(1,472)=.00$, $p=.97$, and robotics experience, $F(1,470)=.51, p=.48$; most students had high levels of robotics interest and equivalent levels of robotics experience as they got older (see Fig. 3a, b). However, there was a significant interaction effect of age and gender on both programming experience, $F(1,474)=7.5, p<.01, \eta_{p}{ }^{2}=.02$, and programming interest, $\mathrm{F}(1,474)=14.22, p<.001, \eta_{p}{ }^{2}=.03$. Therefore, while the marginal means of programming interest and experience were comparable for males and females in the elementary/early middle school age ranges (7-9 and 10-12 years), clear differences in programming interest and experience by gender were shown to emerge in the 13-15 and 16-18 year age ranges, as students enter late middle school/early high school (see Fig. 3c, d).

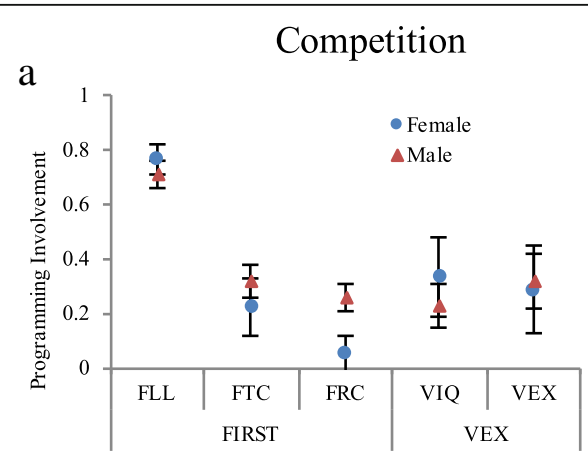

b

Age

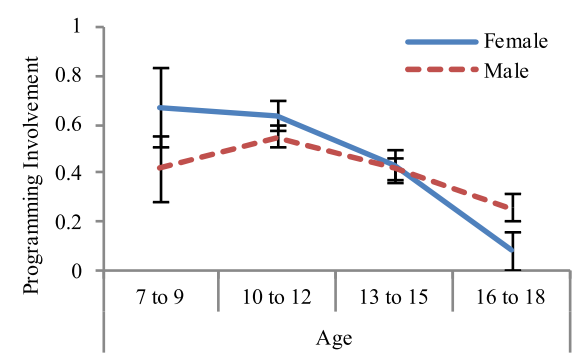

Fig. 2 Marginal means of gendered programming involvement (with SE bars), by a competition and $\mathbf{b}$ age 
Table 3 Sample size, means, and standard deviation for all dependent variables, by gender

\begin{tabular}{|c|c|c|c|c|c|c|c|c|c|}
\hline \multirow[b]{2}{*}{ Variables of interest } & \multicolumn{3}{|c|}{ Male } & \multicolumn{3}{|c|}{ Female } & \multicolumn{3}{|c|}{ Total } \\
\hline & $N$ & $M$ & SD & $N$ & M & SD & $N$ & $M$ & SD \\
\hline Motivation to learn prog. & 321 & 3.4 & 0.7 & 161 & 3.3 & 0.8 & 482 & 3.4 & 0.8 \\
\hline Prog. involvement & 312 & $42 \%$ & & 158 & $44 \%$ & & 470 & $43 \%$ & \\
\hline Robotics experience & 316 & $66 \%$ & & 161 & $68 \%$ & & 477 & $67 \%$ & \\
\hline Prog. experience & 322 & $58 \%$ & & 159 & $49 \%$ & & 481 & $55 \%$ & \\
\hline Robotics interest & 318 & 3.8 & 0.5 & 161 & 3.7 & 0.5 & 479 & 3.7 & 0.5 \\
\hline Prog. interest & 320 & 3.2 & 0.8 & 161 & 3.0 & 0.9 & 481 & 3.1 & 0.8 \\
\hline
\end{tabular}

In our final analyses, we ran an ANCOVA to again test for significant interactions of gender by competition type (model 4) and age group (model 5) on programming involvement, this time including programming interest and experience as covariates. Results show no significant interactions between competition type and gender when controlling for programming experience, $F(4,387)=1.32$, $p=.26$, or especially when controlling for programming interest, $F(4,386)=.72, p=.58$. Therefore, it appears that within robotics competitions, having programming interest and prior experience explain the different levels of programming involvement by gender (see Fig. 4a, c). Similarly, the interaction between age and gender on programming involvement remains marginally significant when including programming experience as a covariate, $F(1,460)=2.76, p=.09, \eta_{p}{ }^{2}<.01$, and becomes not significant when including programming interest as a covariate, $F(1,460)=.14, p<.71$. Therefore, while there may be a small difference in involvement by gender as students get older even when controlling for

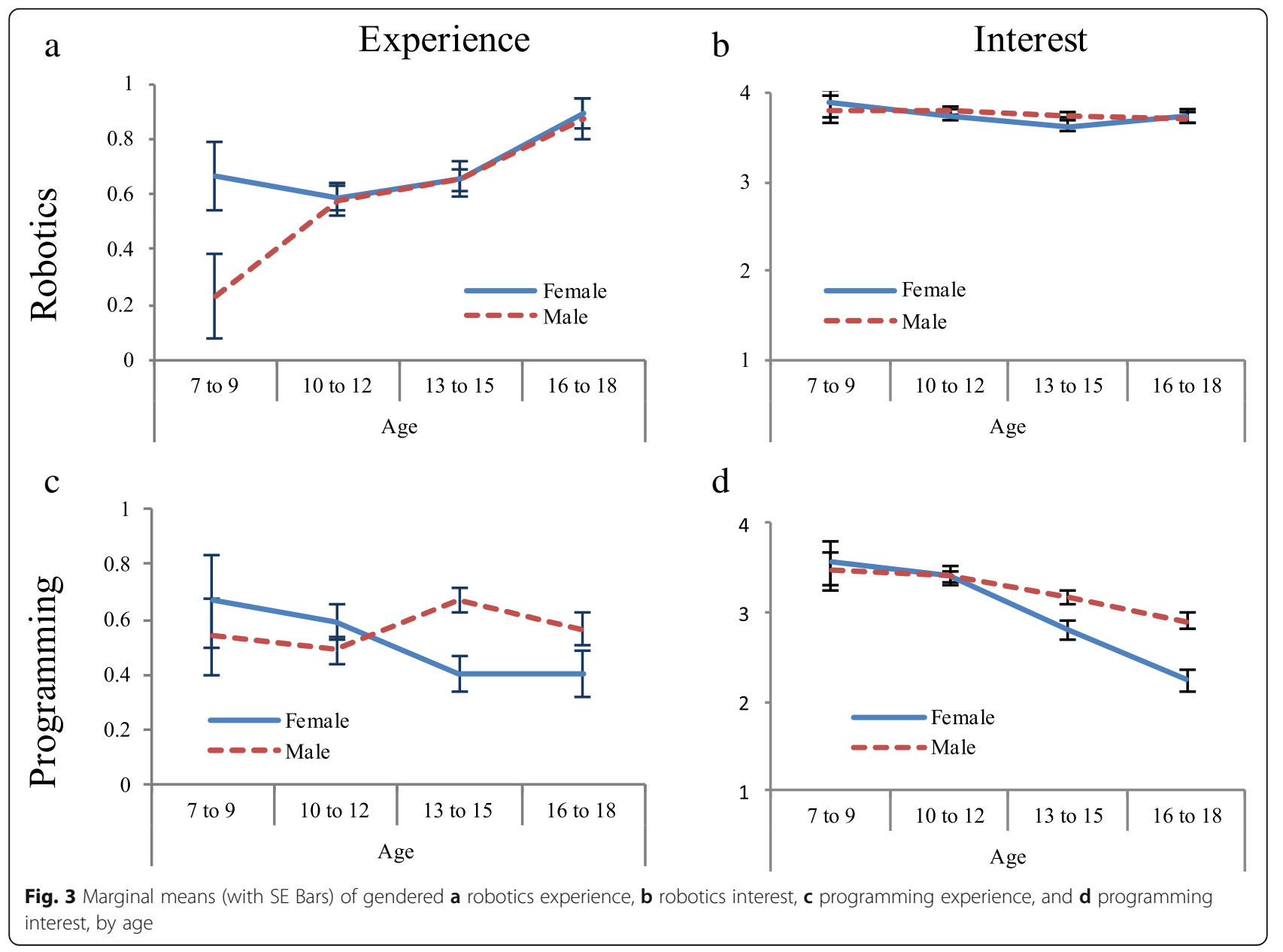




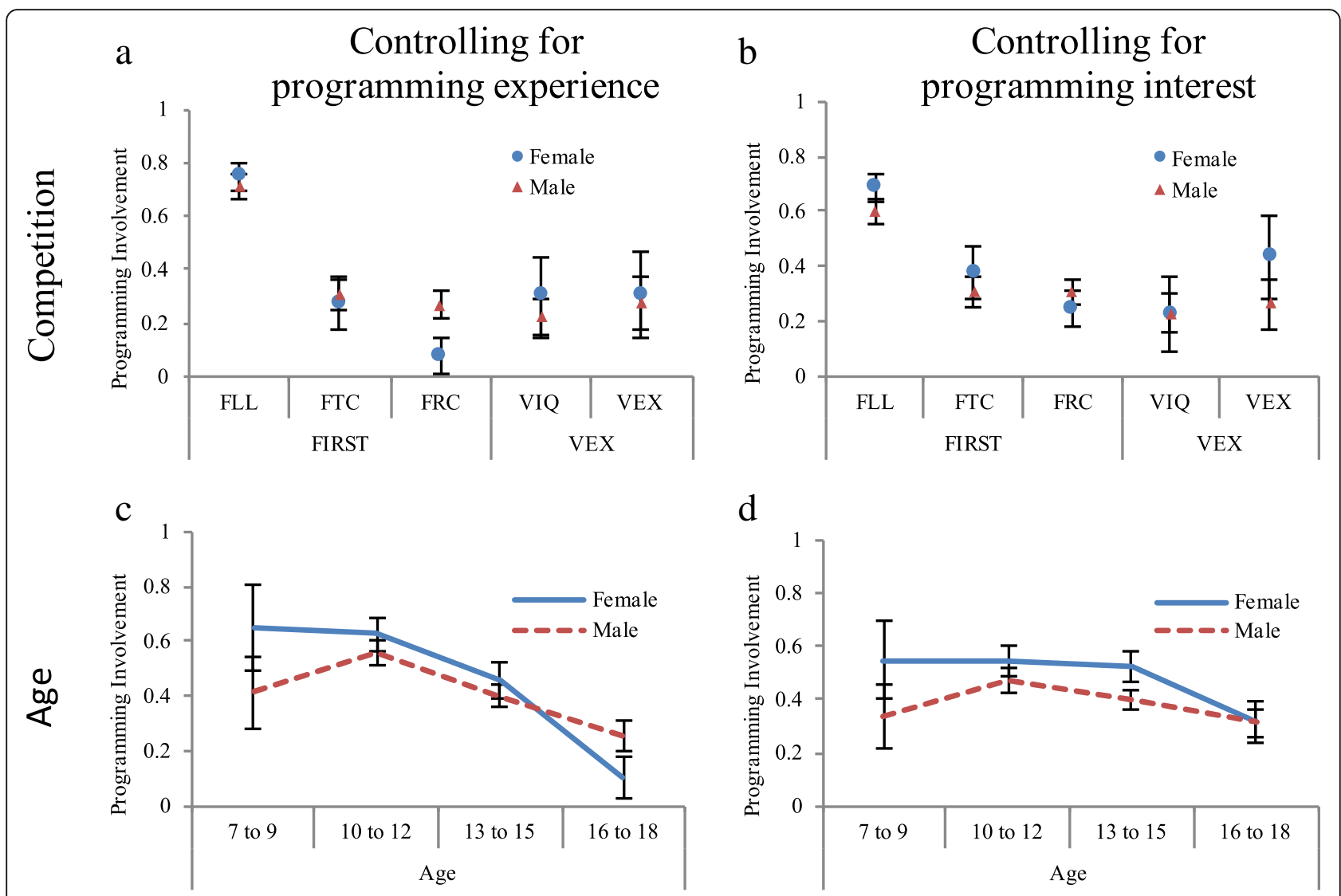

Fig. 4 Marginal means of gendered involvement (with SE bars) in programming, by competition, with covariates of programming a experience and $\mathbf{b}$ interest, and by age, with covariates of programming $\mathbf{c}$ experience and $\mathbf{d}$ interest

prior experience in programming, these differences can be largely explained by related differences in prior programming interest (see Fig. $4 \mathrm{~b}, \mathrm{~d}$ ). It is important to note that across gender and age, the youngest competition, FLL $\left(M_{\mathrm{age}}=11.6, \mathrm{SD}=1.3\right)$, remained the only competition observed involving a large proportion of both male and female students in programming, suggesting the competition main effect is not related to changing patterns in programming interest.

\section{Discussion}

With this study, we build upon prior motivation literature that argues for robotics competitions as an on-ramp for students to pursue additional STEM learning opportunities. Specifically, we investigated the role that programming involvement plays in motivating participants of competition robotics teams to pursue additional learning experiences in programming. We also examined whether or not male and female students were provided with different opportunities to learn programming and if age or the type of competition that students participated in was a significant factor contributing to the kinds of programming involvement those students experienced.
The results from the motivation analyses suggest that students' involvement in programming is related to significant differences in motivation to pursue additional programming opportunities. Essentially, students who saw themselves as being more directly involved with programming were more likely to rate highly in terms of motivation to pursue additional programming experiences. These results are consistent with other active learning studies, which suggest that instruction which directly engages students in the learning process can lead to improvement in student attitudes towards learning (Alemdar \& Rosen 2011; Casad \& Jawaharlal 2012; Prince 2004; Smith et al. 2014). Additionally, it supports claims that developing an identity as "someone who programs" can motivate students to pursue additional programming opportunities (Barton \& Tan 2010; Worsley \& Blikstein 2012). An interesting finding in the current study is that there were no significant differences in motivation to pursue programming for students who programmed collaboratively and those individually responsible for programming. This appears to be inconsistent with studies that suggest collaboration can have positive motivational effects for students 
in robotics contexts (Eguchi 2015; Mitnik et al. 2008). It could be that higher levels of specialization in more advanced competitions produce motivated solo programmers, while more collaborative efforts can be motivational for younger programmers. While these claims lie beyond the scope of this paper, results found here suggest that qualitative follow-up studies of robotics programming involvement might show more nuanced differences in programming motivation between individuals and collaborative groups across age groups and competitions.

Results from the opportunities to learn analyses provide evidence that age and the competition a student participates in are significantly associated with the level of programming involvement they experience and that these opportunities are often different for males and females. Overall, we see a higher level of programming involvement in younger entry-level competitions, but less programming involvement overall in older and more advanced competitions. Most saliently in this study, it was shown that females are more likely than males to be involved in programming in elementary school and in entry-level competitions, but that this difference reverses in high school and more advanced competitions. There is also evidence that the biggest effect on programming involvement is related to an overall decline in programming interest and that this decline in interest also disproportionately affects girls. This finding reflects current trends found in AP and undergraduate CS enrollment and is consistent with studies showing that by the end of high school, females are less likely to elect into AP level CS classes or express interest in pursuing an undergraduate CS major (Doerschuk et al. 2007; Gal-Ezer \& Stephenson 2009; Zweben \& Bizrot 2015). These results also lend support to the gender similarity hypothesis, suggesting that gender differences in achievement and attitudes towards STEM disciplines are not innate but develop over time; instead, pedagogical and socio-cultural features of learning contexts associated with interest may be reliable predictors of girls' continued involvement in CS (Hyde 2005; Spelke 2005). This differential interest is particularly troublesome in environments in which there are many different tasks besides programming and the setup of the environment does not ensure involvement in all of the main tasks by all participants.

\section{Limitations}

The current study is limited by a number of factors. First, the lack of a control group and the correlational relationship between motivation to program and programming involvement prevent strong conclusions about causality. Also, the relatively short survey required the use of single items to represent interest, motivation, and experience in robotics and programming, and such reduced scales are necessarily less precise than longer scales. The limited number of items per construct presents a potential validity problem with the survey instrument utilized in this study. However, even with such short scales, important differences were revealed. Finally, contrasts of different robotics competitions have the potential for selection biases. For example, the samples selected from high school competitions are likely to represent more extreme cases of girls who did not self-select out of robotics competitions. However, we are primarily interested in students who choose to continue to participate in robotics, and further, it is unlikely that girls who self-selected out of robotics were primarily those interested in programming. We would therefore, from a selection bias perspective, expect the ratio of female programmers to remain constant or increase as students grow older, not decline. That this is not the case makes the question of why girls on robotics teams become less interested and involved in programming even more compelling.

\section{Practical considerations}

The patterns in the results have a number of possible interpretations. For example, team responsibilities are typically more segregated in high school robotics teams. It may be that fewer students are involved in programming in older competitions due to a greater compartmentalization of responsibilities, reflecting the more specialized interests of high school students. While lower levels of female programming involvement can be explained by decreasing programming interest, it is possible that this also is an effect of increasing interest in other aspects of the competition (e.g., marketing, fundraising) that are often introduced in larger and more advanced high school competitions like FRC. This may explain the success that smaller and relatively inexpensive competitions like VEX have shown in maintaining female programming interest and involvement, as programming could be offered within a narrower range of possible team responsibilities. It is also possible that different competitions require different levels of programming sophistication in order for teams to be successful, which might impact the resources and effort teams invest in programming.

Prior research has shown that environmental and socio-emotional pressures interact to influence choice of and persistence in computing careers, particularly for traditionally underrepresented groups (Lent et al. 2008). Literature on gender gaps in computing suggest a wide range of factors, including competing with male students for instructors' attention and a lack of female role models in CS, may influence girls' interest and motivation to 
pursue programming opportunities (Gürer \& Camp 2002). As students age, it is reasonable to expect there to be shifts in the particular factors that influence interest and role selection. For example, as robotics participants progress from elementary to middle and high school, greater pressure from peers, parents, mentors, or broader societal expectations to adopt specific gendered roles could exert greater influence on their choice of activity within robotics teams (Kleinman 1998; Renold 2005). Research on gender preference in science has documented that children as young as three are aware of gender role stereotypes and that young girls may be disproportionately aware of these external expectations (Leinbach et al. 1997; O'Brien et al. 2000). Therefore, if a goal of robotics competitions is to increase girls' participation in computer science as well as other STEM fields, passively providing girls with computing opportunities may not be sufficient. Instead, pedagogy and role distribution on robotics teams must be organized to draw explicit connections between the social practices of girls and the disciplinary practices of computer science; there is some evidence that a focus on inquiry-based instruction may provide these opportunities (Goode \& Margolis 2011). Additionally, active recruitment of girls into these activities and of female mentors to serve as role models could be necessary to retain their interest and involvement (Barton et al. 2008; Margolis \& Fisher 2002).

Student intrinsic and extrinsic motivations to join robotics teams, and how their roles are decided once they are there, are interesting lines of inquiry worthy of further research. Informal classroom observations and a small number of follow-up interviews provide initial hypotheses about what kinds of student motivation profiles may exist. For example, when interviewed about their teams, a majority of interviewed students saw team roles as categorized into two groups: "Builders" who are responsible for the mechanical construction of the physical robot, and "Programmers" who are responsible for writing code for the robot to follow. Students' discussions of role adoption largely fell into two common team norms: "Team Success," where students take on roles where they believed they could contribute the most to the team, and "Team Supply," where students fill whatever role is unoccupied or needed at any given time. Specifically, middle school teams stated that they were often assigned task-oriented roles (i.e., completing a particular challenge) rather than static roles within the team.

We hypothesize that an emphasis on a Team Supply framing in middle school teams could explain why these teams are less specialized than high school teams, as students are encouraged to try out different roles as they find their specialty. Alternatively, an emphasis on the Team Success norm would lead to increased internal team pressure towards specialization and therefore discourage students from adopting roles they believe to be atypical of their gender. Particularly, in STEM fields, girls have been shown to be less likely than males to attribute success to their abilities, but more likely to attribute failure to their abilities (Ryckman \& Peckham 1987). Therefore, win or lose, robotics competitions that emphasize team success over equitable participation may differentially affect the interest and involvement of girls relative to their male counterparts. While this does not settle the question of external factors influencing students' incoming self-efficacy beliefs, i.e., what factors lead them to believe occupying one role over another is in the best interest of the team, it does offer some interesting directions for follow-up research when considering girls declining interest and involvement over time. For example, interviews with both students and mentors about the role of competition in the team could help determine whether or not increased focus on winning competitions at the high school level is associated with students adopting a more static and specialized approach to role assignment.

It was less clear from interviews and observations what factors influenced students to initially join robotics teams and if there is any interaction between their pathway to participation in robotics and the eventual role they occupy on their team. That is, there were no clear correlations between students being encouraged to join robotics by parents who are professional engineers, for example, and those students who take on the role of a programmer on that team. Additional structured interviews and longitudinal surveys could help explore the differences that might exist by gender and age based on the different pathways students take to joining robotics teams, as well as explain the different role those students occupy on those teams over time.

\section{Conclusions}

While there are currently measurable differences in participation by gender in the STEM fields, growing evidence suggests that a number of external factors influencing girls' opportunities to learn and participate in STEM activities may predict continued involvement in fields like CS and robotics. Our study suggests that ensuring greater levels of involvement in programming within robotics competitions, particularly for females, may lead to increases in those students' motivation to pursue additional opportunities to learn programming. However, follow-up studies with a team-level analysis will help to illuminate whether individual interest and choice of activity or the particular organization of teams within different competitions are the main factors driving the different levels of programming involvement observed for males and females. 


\section{Appendix}

Table 4 Standardized regression coefficients for correlations between programming involvement and all independent variables (gender, age, and competition type) and covariates (programming experience, robotics experience, programming interest, and robotics interest)

\begin{tabular}{|c|c|c|c|c|c|}
\hline Variables & Model 1 & Model 2 & Model 3 & Model 4 & Model 5 \\
\hline Gender & .019 & .049 & .480 & .080 & .166 \\
\hline Age & - & - & $-.223^{* *}$ & - & $-.113^{\sim}$ \\
\hline FLL & - & & - & & - \\
\hline FTC & - & $-.309^{* *}$ & - & $-.238^{* *}$ & - \\
\hline FRC & - & $-.414^{* *}$ & - & $-.280^{* *}$ & - \\
\hline VIQ & - & $-.295^{* *}$ & - & $-.230^{* *}$ & - \\
\hline VEX & - & $-.198^{* *}$ & - & $-.180^{* *}$ & - \\
\hline ProgInterest & - & - & - & $.370^{* *}$ & $.427^{* *}$ \\
\hline ProgExp & - & - & - & .057 & .029 \\
\hline Gender*age & - & - & $-.482^{\sim}$ & & -.088 \\
\hline Gender* competition & - & {$\left[-.164^{\sim}, .017\right]$} & - & {$[-.086, .028]$} & \\
\hline N & 470 & 399 & 467 & 396 & 463 \\
\hline$R^{2}$ & $<.001$ & .26 & .09 & .37 & .25 \\
\hline
\end{tabular}

Note: ${ }^{* *} p<.001,{ }^{*} p<.01, \sim p<.05$

- not included in the model

\section{Additional file}

Additional file 1: Sample survey items. (DOC $52 \mathrm{~kb}$ )

\section{Acknowledgements}

This work was supported by a grant from the National Science Foundation (DRL 1418199). The opinions are those of the authors and do not represent the policies of the funding agency.

\section{Authors' contributions}

EBW helped to collect and analyze the data and wrote the majority of the manuscript. CDS acted as an anchor author and contributed critically to the design of the study, interpretation of findings, and revisions to the manuscript. $\mathrm{RMH}$ was responsible for the design of the intervention and its materials and helped to administer the surveys. ECB helped to collect and analyze the data and administer the surveys. All of the authors listed in the byline have agreed to the byline order and have approved the submission of the manuscript in this current form.

\section{Competing interests}

The authors declare that they have no competing interests.

Received: 18 May 2016 Accepted: 13 October 2016

Published online: 04 November 2016

\section{References}

Alemdar, M., \& Rosen, J. H. (2011, June). Introducing K-12 teachers to LEGO Mindstorm Robotics through a collaborative online professional development course. Paper presented at the Annual Conference \& Exposition, Vancouver, BC. Retrieved from https://peer.asee.org/18169.

Alimisis, D. (2013). Educational robotics: open questions and new challenges. Themes in Science and Technology Education, 6(1), 63-71. Retrieved from http://earthlab.uoi.gr/theste/index.php/theste/article/view/119/85.

Archer, L., Dewitt, J., Osborne, J., Dillon, J., Willis, B., \& Wong, B. (2012). "Balancing acts": Elementary school girls' negotiations of femininity, achievement, and science. Science Education, 96(6), 967-989. doi:10.1002/sce.21031.

Bandura, A. (1989). Social cognitive theory. In R. Vasta (Ed.), Annals of child development (Vol. 6, pp. 1-60). Greenwich, CT: JAI Press.
Baron-Cohen, S. (2003). The essential difference: the truth about the male and female brain. New York, NY: Basic Books.

Barr, V., \& Stephenson, C. (2011). Bringing computational thinking to K-12: what is involved and what is the role of the computer science education community? ACM Inroads, 2(1), 48-54. doi:10.1145/1929887.1929905.

Barton, A. C., \& Tan, E. (2010). We be burnin'! Agency, identity, and science learning. The Journal of the Learning Sciences, 19(2)، 187-229. doi:10.1080/10508400903530044.

Barton, A. C., Tan, E., \& Rivet, A. (2008). Creating hybrid spaces for engaging school science among urban middle school girls. American Educational Research Journal, 45(1), 68-103. doi:10.3102/0002831207308641.

Blickenstaff, J. C. (2005). Women and science careers: leaky pipeline or gender filter? Gender and Education, 17(4), 369-386. doi:10.1080/09540250500145072.

Brown, J. S., Collins, A., \& Duguid, P. (1989). Situated cognition and the culture of learning. Educational Researcher, 18(1), 32-42.

Bussey, K., \& Bandura, A. (1999). Social cognitive theory of gender development and differentiation. Psychological Review, 106(4), 676. doi:10.1037/0033-295X. 106.4.676.

Casad, B. J., \& Jawaharlal, M. (2012). Learning through guided discovery: an engaging approach to K-12 STEM education. Paper presented at ASEE Annual Conference, San Antonio, Texas. Retrieved from https:/peer.asee.org/21643.

Computer Science Teachers Association, Research Committee. (2009). CSTA national secondary school computer science survey, 2009. Retrieved from https://csta.acm. org/Research/sub/Projects/ResearchFiles/CSTASurvey09CSResults_DCarter.pdf.

Doerschuk, P., Liu, J., \& Mann, J. (2007). Pilot summer camps in computing for middle school girls. ACM SIGCSE Bulletin, 39(3), 4. doi:10.1145/1269900.1268789.

Dunn, O. J. (1964). Multiple comparisons using rank sums. Technometrics, 6(3), 241-252. doi:10.2307/1266041

Eguchi, A. (2015). RoboCupJunior for promoting STEM education, 21 st century skills, and technological advancement through robotics competition. Robotics and Autonomous Systems, 75, 692-699. doi:10.1016/j.robot.2015.05.013.

Else-Quest, N. M., Hyde, J. S., \& Linn, M. C. (2010). Cross-national patterns of gender differences in mathematics: a meta-analysis. Psychological Bulletin, 136(1), 103-127. doi:10.1037/a0018053.

Gal-Ezer, J., \& Stephenson, C. (2009). The current state of computer science in US high schools: a report from two national surveys. Retrieved from Computer Science Teachers Association website, https://csta.acm.org/Research/sub/ Projects/ResearchFiles/StateofCSEDHighschool.pdf.

Geary, D. C. (1998). Male, female: the evolution of human sex differences. Washington, DC: American Psychological Association.

Goode, J., \& Margolis, J. (2011). Exploring computer science. ACM Transactions on Computing Education, 11(2), 1-16. doi:10.1145/1993069.1993076. 
Grover, S., \& Pea, R. (2013). Computational thinking in K-12: a review of the state of the field. Educational Researcher, 42(1), 38-43. doi:10.3102/0013189X12463051.

Gürer, D., \& Camp, T. (2002). An ACM-W literature review on women in computing ACM SIGCSE Bulletin, 34(2), 121-127. doi:10.1145/543812.543844.

Hamner, E., Lauwers, T., Bernstein, D., Nourbakhsh, I., \& DiSalvo, C. (2008). Robot diaries: broadening participation in the computer science pipeline through social technical exploration. Paper presented at the AAAI Symposium on Using Al To Motivate Greater Participation in Computer Science. Retrieved from http://www.aaai.org/Papers/Symposia/Spring/2008/SS-08-08/SS08-08-008.pdf.

Hendricks, C. C., \& Alemdar, M., \& Ogletree, T. W. (2012). The impact of participation in VEX robotics competition on middle and high school students' interest in pursuing STEM studies and STEM-related careers. Paper presented at the ASEE Annual Conference, San Antonio, Texas. Retrieved from https://peer.asee.org/22069.

Holland, D., Lachicotte, W., Skinner, D., \& Cain, C. (1998). Identity and agency in cultural worlds. Cambridge, MA: Harvard University Press.

Hyde, J. S. (2005). The gender similarities hypothesis. American Psychologist, 60(6), 581-592. doi:10.1037/0003-066X.60.6.581.

Hyde, J. S., \& Linn, M. C. (2006). Gender similarities in mathematics and science. Science, 314(5799), 599-600. doi:10.1126/science.1132154.

Kimura, D. (1999). Sex and cognition. Cambridge, MA: MIT Press.

Kleinman, S. S. (1998). Overview of feminist perspectives on the ideology of science. Journal of Research in Science Teaching, 35(8), 837-844. doi:10.1002/ (SICI)1098-2736(199810)35:8<837::AID-TEA2>3.0.CO;2-V

Lave, J., \& Wenger, E. (1991). Situated learning: legitimate peripheral participation. Cambridge, England: Cambridge University Press.

Leinbach, M. D., Hort, B. E., \& Fagot, B. I. (1997). Bears are for boys: metaphorical associations in young children's gender stereotypes. Cognitive Development, 12(1), 107-130. doi:10.1016/S0885-2014(97)90032-0.

Lent, R. W., Lopez, A. M., Lopez, F. G., \& Sheu, H. B. (2008). Social cognitive career theory and the prediction of interests and choice goals in the computing disciplines. Journal of Vocational Behavior, 73(1), 52-62. doi:10.1016/j.jvb.2008.01.002.

Margolis, J., \& Fisher, A. (2002). Unlocking the clubhouse: women in computing. Cambridge, MA: MIT Press.

Melchior, A., Cohen, F., Cutter, T., \& Leavitt, T. (2005). More than robots: an evaluation of the first robotics competition participant and institutional impacts. Retrieved from FIRST Robotics website, http://archive.usfirst.org/ uploadedFiles/Who/Impact/Brandeis_Studies/FRC_eval_finalrpt.pdf.

Mitnik, R., Nussbaum, M., \& Soto, A. (2008). An autonomous educational mobile robot mediator. Autonomous Robots, 25(August), 367-382. doi:10.1007/s10514-008-9101-z.

Modekurty, S., \& Fong, J., \& Cheng, H. H. (2014). C-STEM girls computing and robotics leadership camp. Paper presented at 2014 ASEE Annual Conference, Indianapolis, Indiana. Retreived from https://peer.asee.org/20141.

O'Brien, M., Peyton, V., Mistry, R., Hruda, L., Jacobs, A., Caldera, Y., Huston, A., \& Roy, C. (2000). Gender-role cognition in three-year-old boys and girls. Sex Roles, 42(11), 1007-1025. doi:10.1023/a:1007036600980.

Petre, M., \& Price, B. (2004). Using robotics to motivate 'back door' learning. Education and Information Technologies, 9(2), 147-158. doi:10.1023/B:EAIT. 0000027927.78380 .60 .

Prince, M. (2004). Does active learning work? A review of the research. Journal of Engineering Education, 93(July), 223-231. doi:10.1002/j.2168-9830.2004. tb00809.x.

Renold, E. (2005). Girls, boys and junior sexualities: exploring children's gender and sexual relations in the primary school. London, England: Routledge.

Ryckman, D. B., \& Peckham, P. D. (1987). Gender differences in attributions to success and failure. Journal of Early Adolescence, 7(1), 47-63. doi:0803973233.

Smith, N., Sutcliffe, C., \& Sandvik, L. (2014). Code club. Proceedings of the 45th ACM Technical Symposium on Computer Science Education - SIGCSE'14 (pp. 517-522). doi:10.1145/2538862.2538919.

Spelke, E. S. (2005). Sex differences in intrinsic aptitude for mathematics and science? A critical review. The American Psychologist, 60(9), 950-958. doi:10.1037/0003-066X.60.9.950.

The College Board. (2014). The $10^{\text {th }}$ annual AP report to the nation: subject supplement. Retrieved from http://apreport.collegeboard.org.

U.S. Department of Labor, Bureau of Labor Statistics. (2014). Occupational outlook handbook, 2014-15: Computer and Information Research Scientists. Retrieved from http://www.bls.gov/ooh/computer-and-information-technology/ computer-and-information-research-scientists.htm.

Wing, J. M. (2006). Computational thinking. Communications of the ACM, 49(3), 33. doi:10.1145/1118178.1118215
Worsley, M., \& Blikstein, P. (2012). A framework for characterizing changes in student identity during constructionist learning activities. Paper presented at Constructionism 2012, Athens, Greece. Retrieved from https://tltl.stanford. edu/sites/default/files/files/documents/publications/2012.ConstructionismWB.Framework.pdf.

Zeldin, A., \& Pajares, F. (2000). Against the odds: self-efficacy beliefs of women in mathematical, scientific, and technological careers. American Educational Research Journal, 37(1), 215-246. doi:10.3102/00028312037001215.

Zweben, S., \& Bizrot, B. (2015). 2014 Taulbee survey. Retrieved from the Computing Research Association website, http://cra.org/wp-content/uploads/2015/06/ 2014-Taulbee-Survey.pdf.

\section{Submit your manuscript to a SpringerOpen ${ }^{\circ}$ journal and benefit from:}

- Convenient online submission

- Rigorous peer review

- Immediate publication on acceptance

- Open access: articles freely available online

- High visibility within the field

- Retaining the copyright to your article

Submit your next manuscript at springeropen.com 